\title{
The Effects of Out-of-Home Care on the Development of Social Competence in Sweden: A Longitudinal Study
}

\author{
Michael E. Lamb \\ National Institute of Child Health and Human Development \\ Carl-Philip Hwang \\ Anders Broberg \\ University of Göteborg \\ Fred L. Bookstein \\ University of Michigan
}

\begin{abstract}
In this study, 140 Swedish preschoolers and their parents were first contacted, observed, and interviewed when the children averaged 16 months of age. Subsequently, 53 children entered day-care centers, and 33 were enrolled in family day-care facilities. Further assessments of the children, their families, and their care facilities took place 3, 12, and 24 months after the initial assessment. As predicted, type of child care had no apparent impact on the children's sociability or personality maturity, as measured 24 months after the study began. However, the quality of care received both at home and in the out-of-home care facilities, reported family social support, and child gender helped predict personality maturity (as reported by the mothers using the Block CCQ) and observed social skills with familiar peers and unfamiliar adults.
\end{abstract}

Although there is continuing controversy about the effects on socioemotional development of out-of-home care beginning in early infancy (Belsky, 1986, 1987 , vs. Phillips, McCartney, Scarr, \& Howes, 1987), there is general agreement that day care typically does not have adverse effects on children when it is initiated later (Belsky, Steinberg, \& Walker, 1982; Clarke-Stewart \&

This research was generously supported by the Riksbankens Jubileumsfond of Stockholm, Sweden. We are also grateful to the families and care providers for their cheerful cooperation, to Gunilla Hult and Majt Frodi for assistance in data collection, and to Craig Abbot for assistance with data analysis. This research was initiated while Michael Lamb was at the University of Utah.

Correspondence and requests for reprints should be addressed to Michael E. Lamb, SSED/ LCE/NICHD, BSA Building-Room 331, 9000 Rockville Pike, Bethesda, MD 20892. 
Fein, 1983) and may even enhance the ability to interact with peers (Finkelstein, Dent, Gallagher, \& Ramey, 1978; Harper \& Huie, 1985; Schindler, Moely, \& Frank, 1987). Unfortunately, this conclusion must be hedged with qualifications, because the evidence comes largely from studies involving center-based facilities providing care for socioeconomically homogeneous samples, with few (if any) attempts made to identify pre-existing group differences, and little consideration of family day care or quality of care indices.

The purpose of this study was to examine the effects of the quality of family and center day care on firstborn Swedish children from socioeconomically diverse backgrounds, including in our design measures of family background characteristics and pre-enrollment measures of relevant child characteristics. Earlier we reported the results of analyses concerned with the prediction of social competence assessed one year after enrollment in out-of-home care (Lamb, Hwang, Bookstein, Broberg, Hult, \& Frodi, 1988). Here we examine the prediction of social competence assessed two years after enrollment in a more restrictively defined subsample.

We chose to conduct our research in Sweden to avoid the common confound between parental values/ideology and type of child care. As McCartney, Scarr, Phillips, Grajek, and Schwarz (1982) pointed out, parents in the United States who choose day care may well differ in important ways from parents who choose to care for their children themselves. These differences in parental ideology, rather than the type of care per se, may account for any differences found among children in the different child care groups, especially when no pre-enrollment assessments are involved. We were able to overcome this problem to some extent by limiting our study to families who had expressed a desire to obtain center care for their children.

Because the number of available places is limited in Sweden, we selected our sample only from those families who had formally requested centerbased care. Some were successful in getting places and constituted a group of children receiveing center-based day care. Others were unable to get places in centers, but were instead offered care in family day-care homes; they constituted a second group. A third group of children entered neither centers nor family day-care facilities; they remained at home in the care of their parents. Thus the parents of all of the children had attempted to obtain center care, and the assignment to facilities (both center and family based) was made by public authorities.'

One additional advantage attributable to the Swedish child care system is that the confounding between quality of home care and quality of alternative care is greatly reduced because most facilities are operated under public

' Of course, by matching on parental values and goals, we created a situation in which the parents in only one group might be deemed satisfied. Assuming that values per se might be more significant, we chose to emphasize these for our analyses. 
auspices. In both the United States and Canada, researchers have reported that children from poorer, less child-centered, and more stressed homes tend to be enrolled in alternative care facilities of lower quality (Howes \& Olenick, 1986; Howes \& Stewart, 1986; Kontos, 1987; Phillips, 1987).

In the present study, we attempted to assess the children's characteristics and social style before enroliment in out-of-home care by observing the children's social tendencies with both familiar peers and adults before the care arrangements for children in our three groups (home care, center care, family day care) diverged. Because peer social skills were later assessed as dependent (outcome) measures, it was possible to distinguish the effects of prior social skills from the effects of out-of-home care.

Kontos and Fiene (1987) found that "structural" measures of day-care quality (e.g., staff-child ratio, group size) did not explain variations in child outcome. Using observation-based measures of quality, however, McCartney and her colleagues (1982; McCartney, 1984) and Goelman (1988; Goelman \& Pence, 1987) showed that children receiving high quality out-of-home care developed better language and cognitive skills, were more empathic and sociable, and were better adjusted emotionally than children receiving care of lower quality. Holloway and Reichhart-Erickson (1988) reported that 41/2year-old children who had high quality interaction with their teachers and were in physically well-appointed settings gave more prosocial responses than did children in settings of lower quality, but the indices of quality were unrelated to measures of peer interaction.

Both McCartney et al. (1982) and Goelman (1988) found that family socioeconomic status (SES) - especially as represented by maternal educational level-also affected aspects of cognitive and linguistic development. In the present study, we broadened the assessment of family background to include not only measures of socioeconomic status but also observationally based measures of the quality of home care. Parent-report measures of the extent of paternal involvement in child care were also included in light of the evidence that involvement is associated with peer social skills and aspects of personality development such as locus of control, empathy, and independence similar to those studied here (Lamb, Pleck, \& Levine, 1985; Parke, MacDonald, Beitel, \& Bhavnagri, in press; Radin, 1982). Guided by the previous research (ClarkeStewart \& Fein, 1983), we predicted that quality of home and out-of-home care-whether obtained from center-based or family-based facilities-would ciccount for variations in performance on the outcome measures included here, but that type of care (home care, family day care, center day care) would not have a significant effect except perhaps on the quality of peer engagement.

Perceived social support was also included in the model because of the growing evidence that parental behavior and child adjustment are often influenced by the level of support or social embeddedness perceived by 
parents. Parents who have good social support systems are not only likely to introduce their young children to more social partners of all ages, but can also count on material assistance that enhances both the quality and extent of parental behavior (Colleta \& Gregg, 1981; Crnic, Greenberg, \& Ragozin, 1981; Crockenberg, 1981). Researchers have yet to demonstrate, however, that these effects on parental behavior are translated into differences in child behavior. They ought to be, since variations in the quality of parental behavior are associated with differences in peer social skills and the aspects of personality studied here (e.g., MacDonald \& Parke, 1984). As a result, we expected that children in well-supported families would appear better adjusted and more sociable than would children from more socially isolated families.

Temperament was also assessed in light of the expectation that timid, cautious children, like children who had frequent negative moods, would have fewer successful interactions with peers and, as a result, would become less socially skillful with them. Such children should also be rated lower on ego resiliency, field independence, and ego control than children who were more self-assertive and tended to have positive moods. Such associations were suggested by Thomas, Chess, Birch, Hertzig, and Korn (1963), but we know of no further research on this topic.

In choosing dependent measures, we attempted to assess two broad classes of variables: those concerning the quality of peer play and the degree of sociability with strange adults, and those concerning the child's emergent personality style. Sociability and peer skills have frequently been studied in research on alternative care, and it was thus important to include comparable measures in our attempt to assess the effects of care arrangement (e.g., Clarke-Stewart \& Fein, 1983). The aspects of personality studied here-field independence, ego resiliency, and ego control-have not been examined previously in the day-care literature, but have been considered in the context of research designed to explore the effects of parental behavior, child-parent attachment, and environmental circumstances (see Block \& Block, 1980; Lamb, Thompson, Gardner, \& Charnov, 1985).

The determinants of individual differences in child characteristics both one year and two years after some of the subjects were enrolled in out-ofhome care were assessed using the technique of "soft-modeling" or Partial Least Squares (PLS), which summarizes patterns of correlations among multiple measures of multiple putative constructs, some of which are "determinants" and some "outcomes" of unobservable and indirectly measured social processes (Wold, 1975). The coefficients reported by PLS are tightly tied to actual observable correlations between linear combinations of indicators-no correction for "attenuation" occurs to accommodate vagueness in the model or measurement error. PLS computations assess the coherence of conceptually defined clusters of variables-known as latent variables- 
by examining their patterns of correlations with other latent variables, rather than by examining their patterns of correlations with other members of their own latent variables. In a model, each "latent variable" is computed as a weighted sum of its own indicators by weights that are proportional to the correlations of these indicators with the other latent variable (i.e., the correlations of these predictor indicators and outcome indicators). Proponents of PLS argue that it is ideally suited for longitudinal studies in which multiple measures of multiple constructs are considered (e.g., Bookstein, 1986). Because the procedure emphasizes inter-rather than intra-block correlations, it makes questions of prediction paramount.

Most of the alternatives to PLS, such as L.ISREL, emphasize the fitting of a model involving all of the indicators, whereas PLS substitutes a series of analyses involving pieces of the model in a process that corresponds to the manner in which psychological theory is actually built, accreted over multiple investigations using multiple measures (Joreskog \& Wold, 1982). In Figure 1, a simplified version of this model "tested" here using PLS analyses is depicted. Variables are grouped as latent variables in terms of their conceptual interrelations. Group status was not expected to be important, but quality of home and out-of-home care as well as the other factors discussed above were expected to be influential. The measures themselves are described more fully in the methods section.

\section{METHODS}

\section{Subjects}

The subjects in this longitudinal study were 140 firstborn children ( 70 girls) from Göteborg, Sweden. At the time of initial interview and assessment, they ranged in age from 11 to 24 months ( $M$ and median $=15.9$ months; $S D=2.9$ months). Names of two-parent families on the waiting lists for child care facilities were obtained from municipal authorities in all areas of the city. Parents were then individually contacted by the research staff and invited to participate in the research. Parents understood that their decision regarding participation would have no effect on their success in obtaining child care assignments. Approximately $75 \%$ of the eligible families contacted agreed to participate, and only 5 of the 145 families initially recruited dropped out of the study. As indicated in Table 1 (see results section), Hollingshead (1975) scores showed that the children came from a range of middleclass backgrounds.

The representativeness of our sample was determined by comparing the children's characteristics with those of a representative sample of $10 \%$ of all 10- to 24-month-old children in Göteborg (Broberg \& Hwang, 1986). With respect to maternal and paternal Hollingshead scores, maternal age, and paternal age, the families with children in our home care and day-care 


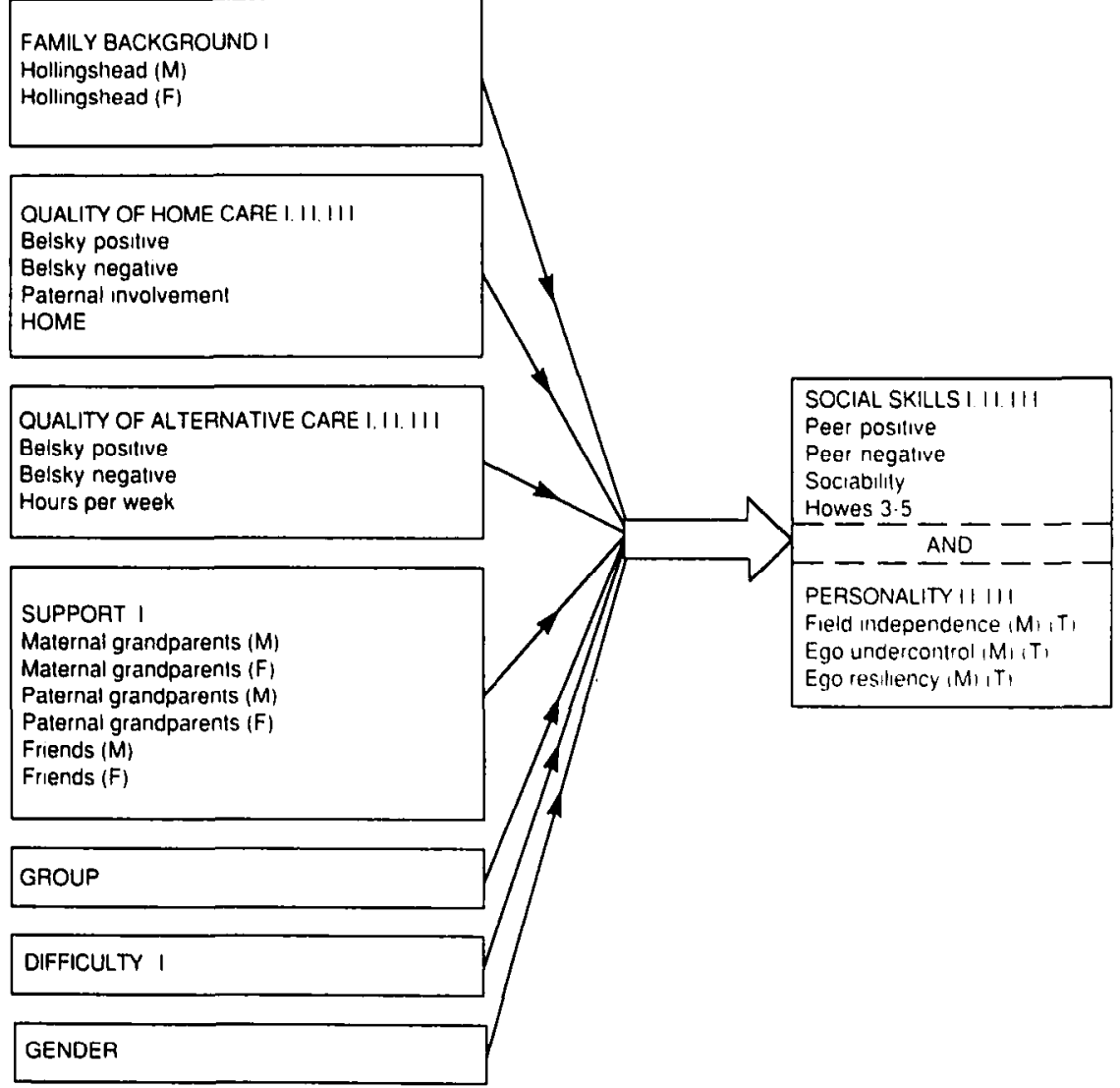

Figure 1. Simplified version of the model. Letters in parentheses indicate the source of the information: $\mathbf{M}=$ mother, $F=$ father, $T=$ care provider. Roman numerals indicate the phases in which the data were gathered. Care providers completed the personality ratings only in phase II.

groups did not differ from two-parent, one-child families with these care arrangements in the larger sample. However, the children in our family daycare group had parents who had significantly higher overall Hollingshead scores $(M=47.80$ vs. 37.70$)$ than did family day-care children in the city. The mothers of children in the family day-care group were also significantly older $(M=30.85$ years vs. 28.64 years, $p<.05)$. The reasons for these differences are not clear.

\section{Procedure}

Although all of the subjects were drawn from waiting lists for center-based child care facilities, the shortage of available slots ensured that the majority 
could not be accommodated. Some of these remained in the full-time care of their parents; others were offered and accepted family day-care placements. Subjects were thus divided into three groups: center day care $(n=53)$, family day care $(n=33)$, and home care $(n=54)$.

After agreeing to participate in the study, all of the families were visited in their homes by a member of the research staff. During this visit, demographic data were gathered and parents were interviewed about their social networks; relative parental involvement, using a full day recall diary similar to that employed by Robinson (1977); and their child's temperament, using the Swedish translation of Rothbart's (1981) Infant Behavior Questionnaire (IBQ) prepared by Lamb, Frodi, Hwang, and Frodi (1983). The child's initial response to the visiting adult was also scored, using Stevenson's and Lamb's (1979) procedure for assessing stranger sociability. A second visit was then arranged. On this occasion, the child was observed interacting at home for 30 minutes with a familiar peer (selected by the parents) of roughly the same age. The observer also rated the quality of home care, using Belsky's and Walker's (1980) checklist and Caldwell's (1970) HOME inventory.

Those children in one of the alternative care groups began out-of-home care within two weeks of the two home visits. Six weeks later their child care facilities were visited by a members of the research staff who rated the quality of care, using Belsky's and Walker's (1980) checklist.

Both one year and two years after the first interview the families were visited again. During one visit, stranger sociability was again assessed, and the mothers completed a Q-sort description of their child, using Block's and Block's (1980) California Child Q-set (CCQ), which measures field independence, ego resilience, and ego control. During a second visit, the child was again observed interacting for 30 minutes with a familiar peer of the parents' choice. Again, quality of home care was sampled, using the Belsky and Walker checklist and Caldwell's HOME inventory. On a subsequent visit to the child's child care facility (for children in the two out-of-home groups), the quality of care was sampled, using the Belsky and Walker checklist, and a teacher who knew the child well described her or his personality, using the CCQ.

On the basis of these procedures, the measures described below were derived.

\section{Measures}

Child Characteristics. Using the Rothbart (1981) IBQ, a standardized parent report measure of infant temperament, we assessed child characteristics. Responses to 87 items yield scores on six dimensions: activity level, positive emotionality, fear, anger-frustration, soothability, and undisturbed persistence. Internal reliability coefficients for the six dimensions at 3,6 , and 9 months ranged from .72 to .82 , with a mean of .78 , based on a sample 
of 463 (Rothbart, 1981). Rothbart $(1981,1986)$ also showed temporal stability over assessments at 3,6 , and 9 months (coefficients varied across scales in a predictable fashion), as well as convergence between observed behavior and parental reports, using the IBQ. Unfortunately, temporal stability and convergent validity in the second year of life have not been studied, although the IBQ has been widely used with children of this age (e.g., Thompson \& Lamb, 1984). Significant mother-father or mother-babysitter agreement was found in previous studies in Sweden (Lamb et al., 1983) and in the United States (Rothbart, 1981). In the present study, analyses involved only one composite measure because we wished to reduce the total number of variables included in the analyses. Following Frodi, Lamb, Hwang, Frodi, Forsstrom, and Corry (1982), we computed a score for perceived difficulty by adding the IBQ score for anger-frustration to the inverse of the scores for positive emotionality and for soothability, before dividing by 3 . Possible scores thus ranged from $I$ to 7 , with high scores indicating that the child's temperament was perceived to be difficult. This composite measure was inspired by the writing of Thomas et al. (1963) concerning the components of temperamental difficulty, but the validity of the composite, constructed using scores on Rothbart's IBQ, is unknown.

Family Background and Home Environment. We tapped these factors using a number of measures. First, maternal and paternal Hollingshead scores-weighted sums of the education and occupation scores for each parent-were computed as instructed by Hollingshead (1975). The possible range for each is from 8 to 66 , with high scores denoting high social status. Although developed in the United States, the Hollingshead scales have been employed successfully in previous studies conducted in Sweden (e.g, Cochran, 1977; Frodi et al., 1982).

Second, observers completed the HOME inventory as instructed by Caldwell (1970). On the infancy version of this well-known inventory, there are 45 items measuring the amount of stimulation available in the home environment. The inventory yields scores on six subscales as well as a total score, but we considered only the total score in our analyses in an effort to reduce the number of dependent measures. In previous research, the total score has proved to be reliable and to have good external validity (e.g., Elardo, Bradley, \& Caldwell, 1975, 1977). Elardo et al. (1975) reported an internal consistency coefficient of .89 for the total scale. Test-retest reliability between assessments at 6 and 24 months was .62 (Caldwell \& Bradley, 1979). The infancy version was completed in both phase I and phase II of the present study.

In phase III, observers completed four subscales-IV (pride, affection, and warmth), VI (modeling and encouragement of social maturity), VII (variety of stimulation), and VIII (physical punishment) - of the preschool version of HOME (Caldwell \& Bradley, 1984), which was more appropriate 
for the age of the children at this time. The four subscales selected were chosen because pilot testing revealed little variability on the others. Internal consistency estimates for these 7-, 5-, 9-, and 4-point subscales were .75, $.53, .69$, and .59 , respectively, in the standardization sample of 117 families (Caldwell \& Bradley, 1984). Between 36 and 54 months, stability coefficients were $.44, .29, .48$, and .05, respectively (Caldwell \& Bradley, 1984). In the standardization sample, scores on all four subscales (as well as the total score) were significantly correlated with contemporaneous measures of IQ as well as IQ scores obtained 18 months later. Scores on subscale VII (and the total score) were predictive over a 48-month span (Caldwell \& Bradley, 1984). Scores on the four subscales were combined into a single index for analytic purposes in this study.

Third, the Belsky and Walker checklist was also used to assess the quality of care obtained at home. The checklist includes 13 positive and 7 negative events, and the observer notes whether each occurred at least once during a 3-minute "spot" sample unit. The positive events were the following: care provider positive regard, care provider verbal elaboration, care provider heightened-exaggerated emotional display, care provider empathizes, routine made into learning experience, care provider engaged with more than one child, care provider engaged while doing routine maintenance, care provider engaged in nonstructured attention focusing, care provider facilitates peer relations, care provider on floor involved, care provider distant involved, child explores nontoy object, and child happy. The negative events were the following: child crying, care provider prohibits some child action, child in restrictive device, children waiting, care providers in nonchild conversation, child uninvolved-aimless, and routine as routine. The environment was sampled three or four times per occasion, and the numbers of negative and positive items per occasion were then averaged for analysis. Further details are provided in the Belsky and Walker (1980) scoring manual.

The quality of care provided in the alternative care settings was also assessed, using the Belsky and Walker checklist, and completed in the manner just described. The alternative care settings were assessed three times: 3 months after enrollment, 9 months later, and 12 months after that. Pilot research in the United States with this checklist indicated a remarkable sensitivity to enduring aspects of the quality of care so that, whether or not different items were checked each time, the correlations between scores on assessments made a week apart were .85 for positive scores and .90 for negative scores ( $N=30$ environments), with no differences in the reliability for home and alternative care settings (Lamb, Steinberg, \& Knuth, unpublished data).

Support. Twenty four questions were asked of mothers and fathers about the contacts with and support received from maternal and paternal grandparents, other relatives, friends, and neighbors. Mothers' and fathers' 
responses were used to create independent composite scores on the basis of conceptual relatedness, and the internal coherence of the scales was later assessed, using Cronbach's alpha. Items were dropped if they did not achieve coefficients greater than .30 with the total score; 13 of the items were thus eliminated from consideration. Three different composite measures were then computed for each parent: perceived support from maternal grandparents, perceived support from paternal grandparents, and perceived support from friends and neighbors. Each of the four grandparent support measures contained three items-the mother's report and the father's report of the number of contacts with the relevant grandmother and grandfather, and the frequency of visits to the relevant grandparents. The two friendneighbor support measures each contained five items, referring to the number of neighbors known, the frequency of chatting with them, the frequency with which their children played, the frequency of having coffee together, and the frequency of sharing toys or household items. Alpha coefficients for the maternal support from maternal grandparents was .57, from paternal grandparents .62, and from friends-neighbors .79. Alpha coefficients for the same variables based on paternal reports were $.57, .58$, and, .79, respectively.

Child Personality. The child's scores for field independence, ego resilience, and ego under-control were computed by correlating the ratings assigned by the mothers or care providers on the 100-item CCQ, with the criterion scores for the most field independent, ego resilient, and ego undercontrolled child supplied by Block and Block $(1979,1980)$. These correlation coefficients were then used as scores in all subsequent analyses. The items are scored in such a way that high scores denote field independence, ego resilience, and ego under-control. Although the standardizing longitudinal study conducted by Block and Block (1980) did not involve children under 36 months of age, J.H. Block (personal communication, 1978) considered it appropriate for most children in the third year of life.

Peer Skills. The peer interaction sessions were divided into consecutive 15 -second observation units, followed by 15 -second breaks for data entry. For each observation unit, the observer recorded the incidence of any of 23 discrete behaviors or states and also rated the quality of the peer play observed, using the Howes (1980) 6-point rating scale $(0,1,2,3,4,5)$, which has demonstrated Guttman-scale qualities. On this scale, 0 is scored when no play is observed, 1 when the children are engaged in noninteractive parallel play, 2 when there is parallel play with mutual regard, 3 simple social play (one child directs a social bid to the other), 4 complementary and reciprocal play with mutual awareness, and 5 complementary and reciprocal social play. Further details are provided in the Howes (1980) coding manual. Howes (personal communication, September 15, 1986) reports test-retest reliabilities over a 4-week period of .91 and .93 in samples of 41 and 329 
preschoolers, respectively. Howes (1980) found that amount of experience with peers predicted higher scores in two separate samples, but found no relation to age of child in a sample of 10- to 22-month-olds or another sample of 18- to 43-month-olds.

Three peer interaction scores were derived for analysis: positive peerrelated behaviors (the sum of the observed instances of initiate play, imitate, vocalize, touch, proffer, accept, and laugh-smile), negative peer-directed behaviors (the composite total for reject bid, turn away, take away toy, take toy from, have toy taken from, throw, defensive struggle, of fensive struggle, strike-hit, and cry), ${ }^{2}$ and Howes 3-5 measure, the total number of units during the play was rated a 3,4 , or 5 on the Howes scale. ${ }^{3}$

Sociability. In the initial phase, sociability was assessed upon the observer-interviewer's arrival at the child's home, using a procedure developed and more fully described by Stevenson and Lamb (1979; Thompson \& Lamb, 1983). The child's response was rated in each of eight contexts: initial reaction to stranger and reactions to offer of toy, to attempted initiation of game, when given floor freedom, to offer of toy when on floor, to attempted initiation of game, to attempted pick up, and to stranger's departure. Rating was on a 5-point scale, with 1 indicating a fussy, unfriendly response and 5 indicating an outgoing, positive response. In addition, the observer recorded her or his overall impression of the child's sociability on a 9-point scale. All ratings were then added to yield a measure with a possible range of 9 to 49. Stevenson and Lamb (1979) reported significant correlations $(r=46)$ with sociability in a test situation, as well as significant test-retest reliability between multiple assessments in both the same $(r=.73)$ and different $(r s=.49, .40)$ contexts over a 2 -week period.

In phase II the sociability assessment procedure was altered to accommodate the increased age of the children. The child's response was rated in each of five contexts: initial reaction, response to request to approach, reaction to initiation of turn-taking game, response to verbal query, reaction to stranger's attempt to pick up and read to child. Rating was on a 5-point scale similar to that used in phase $I$. In addition, the observer recorded his or her overall impression on a 9-point scale. When the ratings were summed, the possible range was 6 to 34 .

In phase III, the sociability measure was again changed to accommodate the increased age of the children. On this occasion a single 9-point scale, measuring the observer's overall impression, was employed.

\footnotetext{
2 In phase III, the components of these composite scores changed slightly in recognition of the children's increasing age.

${ }^{3}$ In a previous report, Lamb et al. (1988) used as a measure the total number of occasions on which the play was rated as a $2,3,4$, or 5 . The resulting Howes 2-5 measure correlates very highly with the Howes 3-5 measure used here. We have chosen to use the latter measure because it appears more appropriate for the older children now included.
} 


\section{Reliability}

All observations (peer interaction, sociability, quality of care indices) were conducted by one of three individuals who trained together, using videotapes and pilot subjects, until achieving criterial degrees of reliability. For the peer interaction and HOME inventory codes, criterion was set at $80 \%$ exact agreement; for sociability and the Belsky and Walker items, criterion was set at $90 \%$. Once data collection began, $15 \%$ of the sessions were conducted by two of the observers, working simultaneously but independently. Reliability coefficients were within $5 \%$ of the criterion levels mentioned above in each of the subsequent reliability assessments. It was impossible to keep observers blind with respect to the group status of the children, but they were unaware of the explanatory model guiding the research or of the predictions.

\section{RESULTS}

Of the 140 children who remained in the study through phase III, 115 maintained the original care arrangement through at least phases I and II, while 84 maintained the same arrangement through phase III. Preliminary analyses revealed no significant differences between those children and families who changed arrangements and the remainder of the sample. All analyses reported here were computed twice: once on the subsample of 115 and once on the subsample of 84 . On occasion, the results obtained with the PLS technique varied, depending on the sample employed; in these cases both sets of results are reported. In other cases, we report only those based on the most restrictively defined subsample of those 84 children and families who maintained the same care arrangements throughout.

\section{Traditional Univariate Analyses}

Initial analyses were conducted using 3 (group: home care, center care, family day care) by 2 (sex of child) ANOVAs. There were group differences on age at enrollment, $F_{2,78}=4.01, p<.022$; fathers' Hollingshead scores, $F=5.51, p<.006$; mothers' Hollingshead scores, $F=4.40, p<.05$; and maternal reports of ego control in phase $\mathrm{III}, F=3.32, p<.041$. Inspection of the means presented in Table 1 reveals that children in the family daycare group were younger, came from families of higher social status, and were rated less ego-controlled in phase III than were children in the other two groups. Note that there was only one group difference (out of 21) on an outcome variable, about the number that one would expect to occur by chance. The difference itself was not consistent over time and involved the smallest group. The most conservative conclusion, therefore, is that type of care had no clear or consistent effect on social competence. This conclusion was substantiated by the results of the more sophisticated multivariate analyses reported below. 


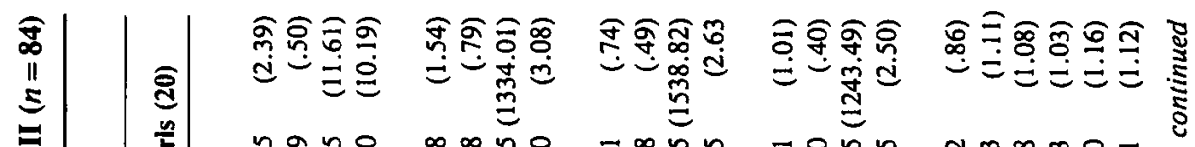

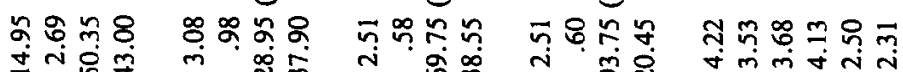
文官孚

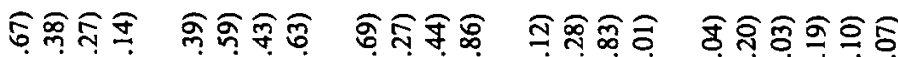

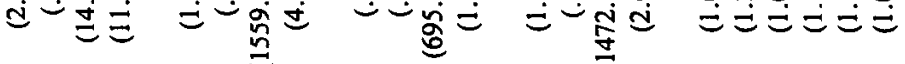

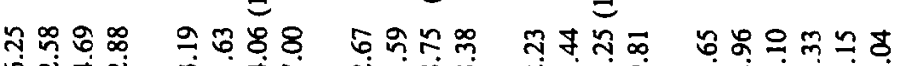

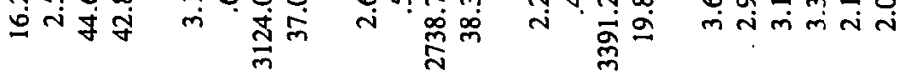

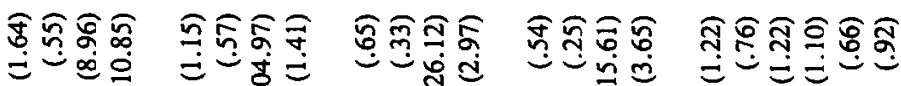

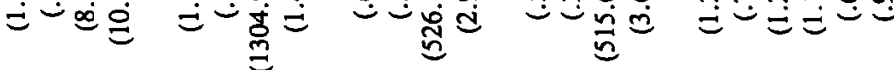

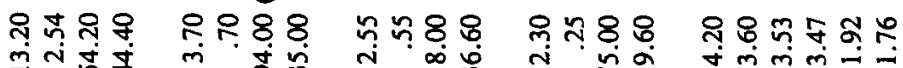

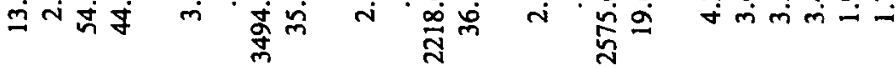

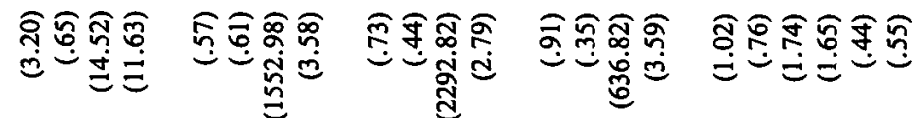

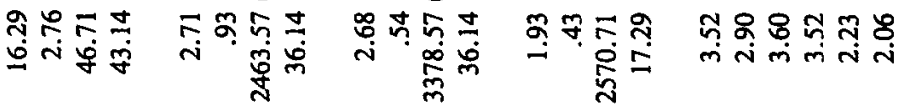

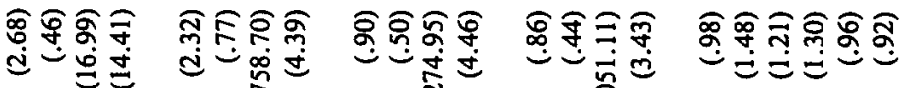

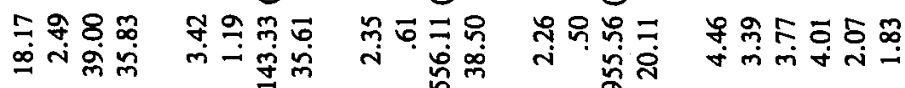

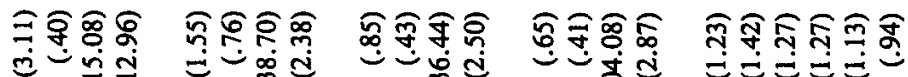

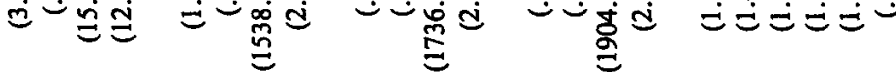

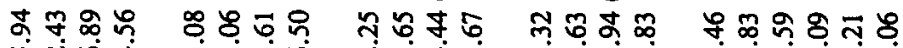
ऽN它

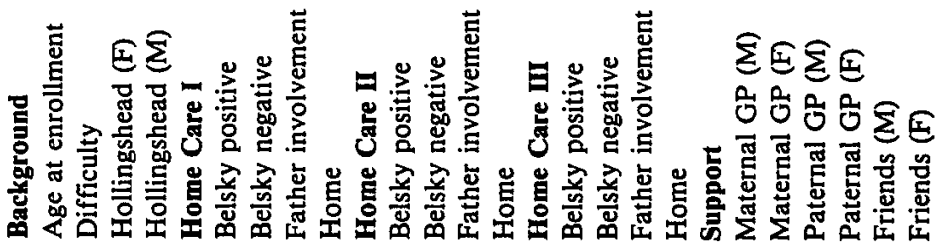




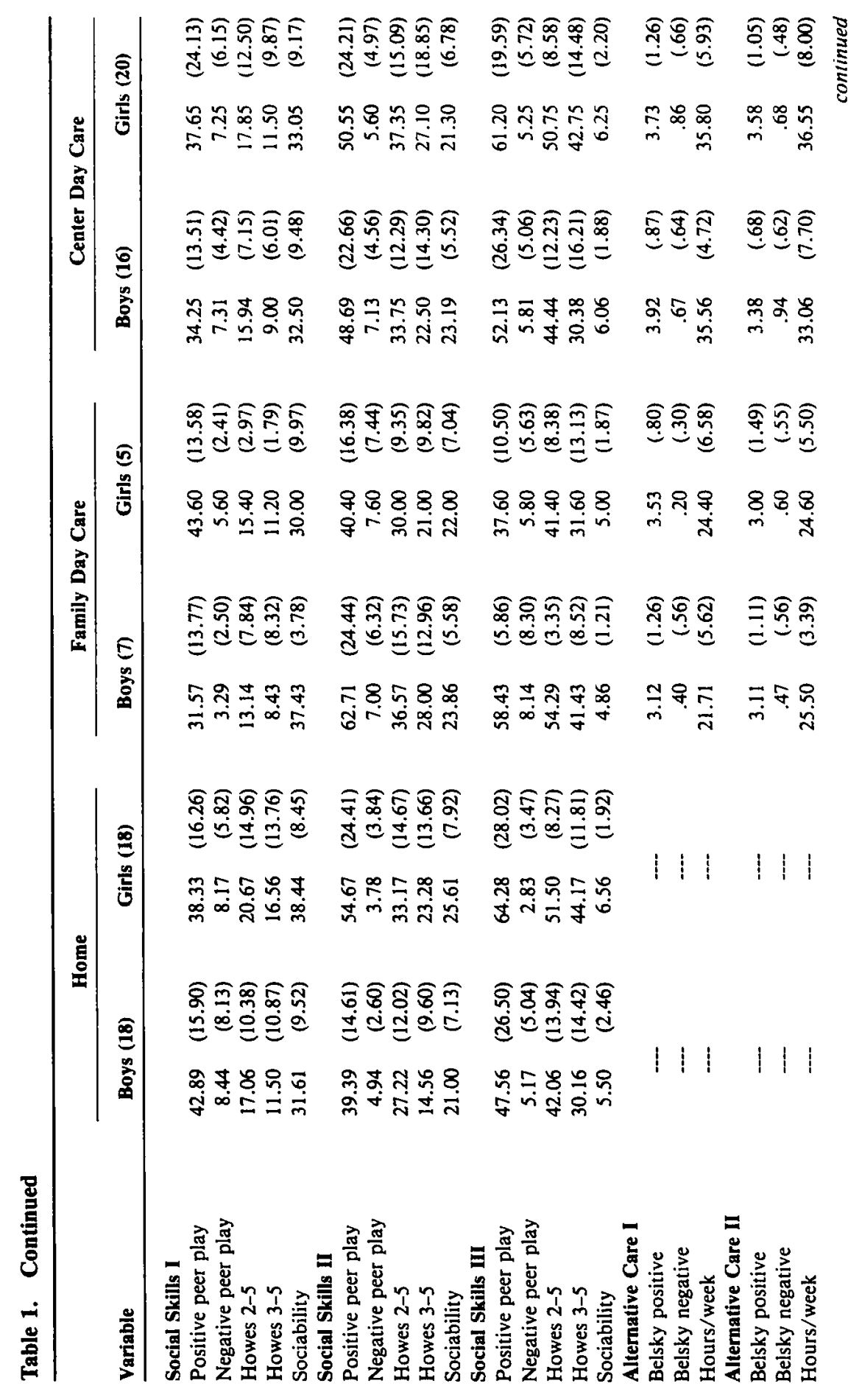




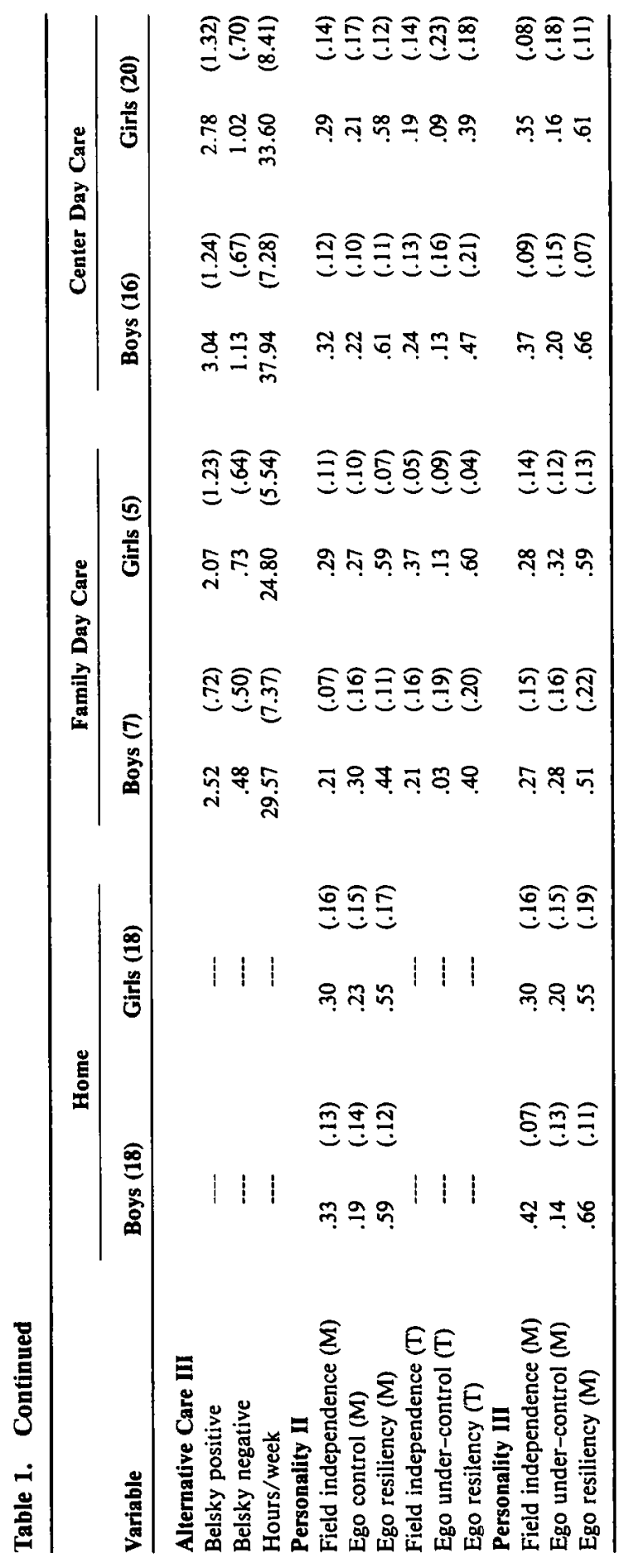


Within the two out-of-home care groups, there were group differences in 2 (group: center care, family day care) $\times 2$ (sex of child) ANOVAs on the frequency of negative Belsky scores in the alternative care facility both at phase I, $F_{1,44}=4.90, p<.032$, and at phase III, $F=4.83, p<.033$, as well as on the hours per week variable in each phase, $F_{I}=47.96, p<.000 ; F_{I I}=15.60$, $p<.000$; and $F_{I I}=4.27, p<.045$. More negative events were noted in the center care facilities, as would be expected given the greater number of children present and thus the greater likelihood that negative events could be observed using a spot scan measure. In addition, the center care children consistently spent more time in out-of-home care than did the children in family day care facilities.

There were significant effects for sex of child on 3 of 54 analyses. They reveal higher HOME scores in phase I for boys, $F=6.25, p<.015$; higher social participation (Howes 3-5) scores for girls in phase III, $F=10.36, p<$ .002 ; and higher reported field independence on the part of boys in phase III, $F=5.52, p<.021$. These differences are so inconsistent and so few in number relative to the number of analyses conducted that we choose not to discuss them further. The same is true of the four significant group $\times$ sex of child statistical interactions: age of enrollment $F_{2.78}=5.91, p<.004$; Howes 3-5 in phase II, $F=3.42, p<.038$; field independence in phase II according to teachers, $F=5.26, p<.027$; and ego resiliency in phase II according to teachers, $F=4.61, p<.037$ ).

Overall, therefore, these analyses reveal few group differences on either determinants or outcome measures. The children in the family day care group appeared to come from more advantaged backgrounds, to experience fewer negative incidents in their care facilities, and to spend less time in outof-home care than did children receiving center-based care. These differences notwithstanding, there are no reliable group differences on the multiple measures of social competence employed in this study.

\section{Multivariate Longitudinal Analyses}

Figure 2 summarizes PLS analyses assessing the prediction of individual differences in social skills measured in phase III. The net $R$ for the combined prediction was a respectable .64 . Inspection of the figure indicates that the quality of home care, the quality of out-of-home care, social skills at time II, and the children's gender all contributed significantly to the prediction of observed social skills in phase III. Background (primarily social class) and support had modest associations, and perceived infant difficulty and group status were unrelated to social skills, as assessed here. Children who were more sociable and playful with both peers and strange adults came from homes receiving higher scores on Caldwell's HOME inventory and had less involved fathers. They also spent more time in out-of-home care facilities characterized by low scores on both the positive and negative scales of the Belsky and Walker checklist. Girls were more sociable than boys. The 


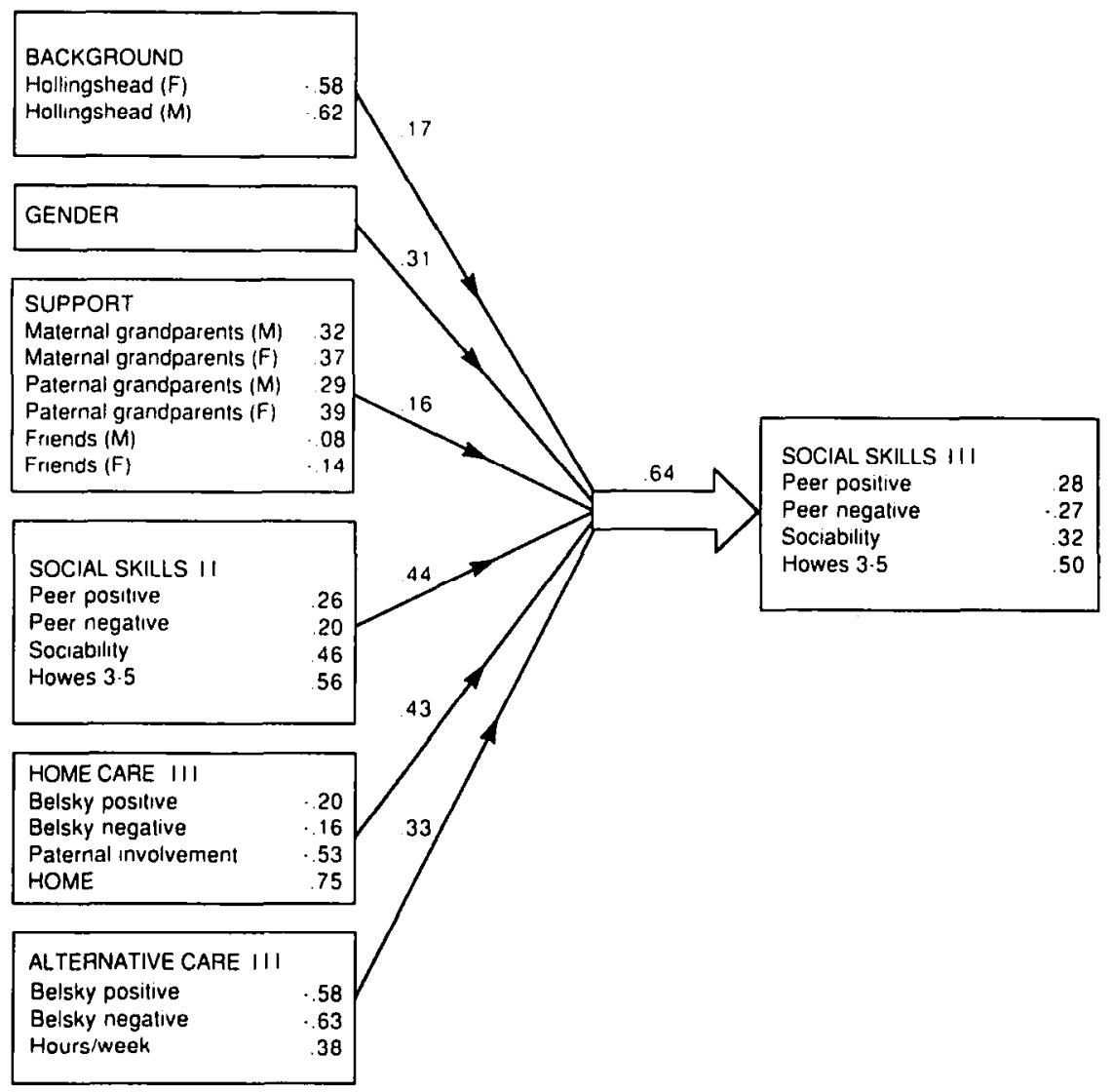

Figure 2. Determinants of social skills as assessed in phase III. Letters in parentheses indicate the source of the information: $\mathbf{M}=$ mother, $F=$ father. Roman numerals designate the phase in which the data were gathered. Difficulty and group status had no explanatory value and so are not included in this figure.

prediction by gender, quality of home care, and quality of alternative care remained substantial (net $R=.57$ ) even when prior social skills were not included in the model. As Figure 2 shows, this latent variable was the best predictor of individual differences in social skills at time III. This indicates that the autocorrelation between successive measures of social skills is substantial, but that knowledge of prior social skills does not much enhance the degree of prediction achieved using the other predictor variables alone. Presumably this is because scores on the earlier measures of child social skills are themselves determined by variations in this group of determinantsincluding child gender, quality of home care, and quality of alternative care (see Lamb et al., 1988). 
The coefficients were very similar (net $R=.63$ ) when the model was computed again, using the larger sample $(n=115)$ of children who had remained in the same group through the first two phases but who may have changed care arrangements between phases II and III. Even so, the relative importance of the hours per week variable within the quality of alternative care latent variable decreased from a coefficient of .38 to .10 , the gender latent variable had a coefficient of only .16, while the coefficient for support rose to .21. In neither model did group assignment have any impact on the social skills III latent variable.

Figure 3 summarizes the predictive model examining the determinants of personality ratings in phase III. The figure shows that the latent variables of support, quality of home care III, quality of alternative care III, and personality II all helped explain equivalent proportions of the variance in the personality ratings. More mature ratings on the personality Q-sort were obtained at time III when the children had received more mature ratings from their mothers at time II, when parents reported higher levels of support (especially from friends and neighbors), when the home was more stimulating and fathers were more involved, and when the quality of alternative care was poorer, the longer the amount of time spent there! Not surprisingly, prior personality maturity was the best predictor, with an "autocorrelation" coefficient of .59. When the earlier personality ratings were excluded from the model, the net $R$ fell from .63 to .46 , but the relative importance of the other latent variables, and indicators thereof, was unchanged. Again, this probably reflects the fact that the earlier personality characteristics were themselves predicted by variations in family background, support, and the quality of care (see Lamb et al., 1988).

When the model was recomputed with the larger sample $(n=115)$ of children who maintained the same care arrangements through at least phase II, the predictive importance of the quality of alternative care and support latent variables fell to .16 and .15 , respectively, while the coefficient for personality II rose to .67 . The net $R$ for the model rose nonsignificantly to .68. Coefficients within the alternative care latent variable changed dramatically, such that positive Belsky scores and hours per week were positively and substantially ( $r s=.62$ and .77 , respectively) associated with more mature personality ratings. Coefficients within the support and personality latent variables also changed, albeit in inconsistent and uninterpretable ways.

\section{DISCUSSION}

Using two different analytic strategies, we report above that the type of child care received by children over a two-year period had no significant effect on their observed social skills or reported personality. The quality of care received both at home and in alternative care settings was influential, 


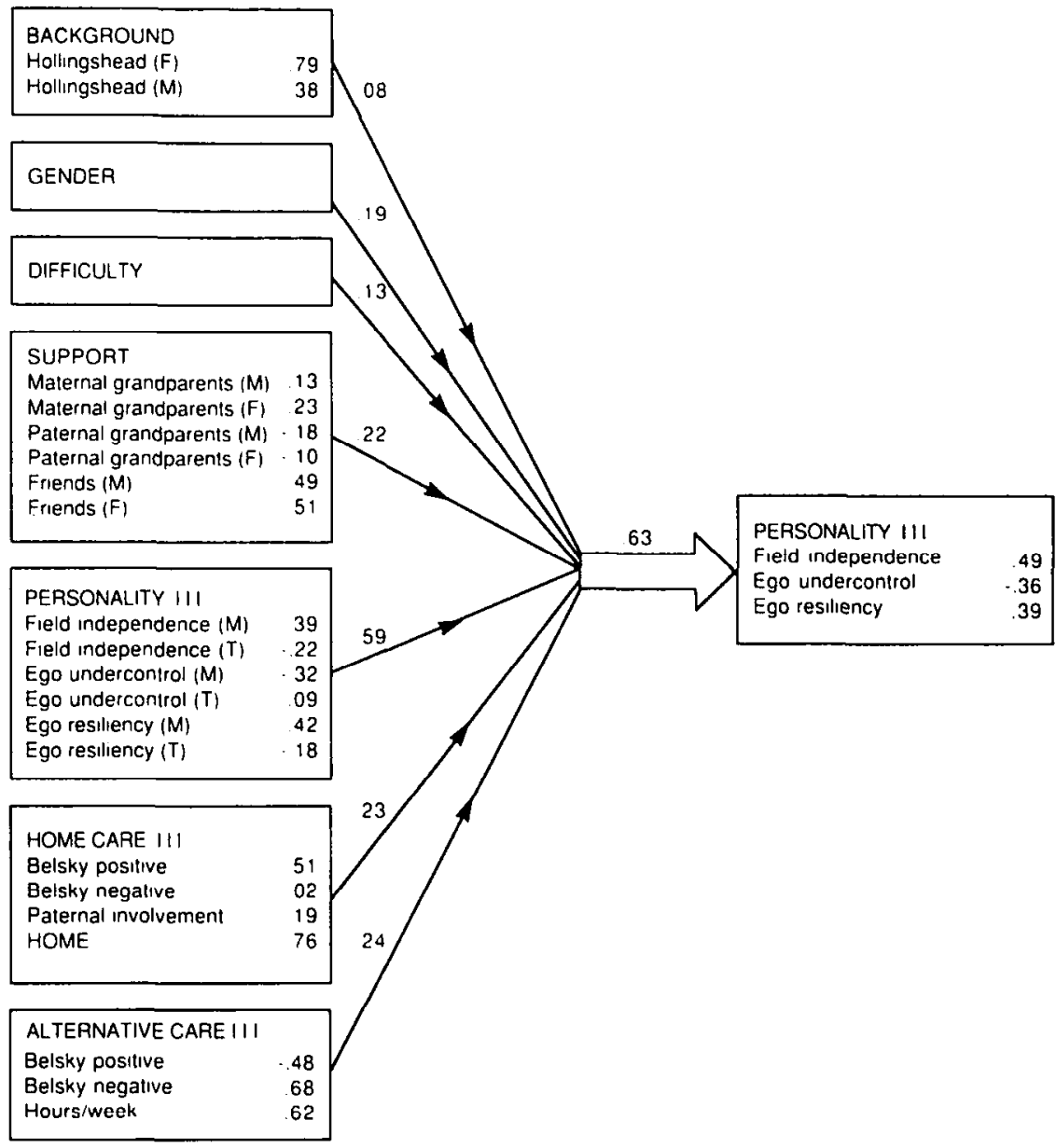

Figure 3. Determinants of maternal personality ratings in phase III. Letters in parentheses indicate the source of the information: $M=$ mother, $F=$ father, $T=$ care provider. Roman numerals indicate the phases in which the data were gathered. Group status had no explanatory value and so is not included in the figure.

however, as were measures of reported social support, prior social competence, and child gender. Scores on Caldwell's HOME inventory had the most reliable and consistent predictive value.

We correctly anticipated that type of child care would not be influential. This finding is largely consistent with the results of a number of studies indicating that out-of-home care beginning in the second year of life does not have a reliable and consistent effect on emergent social competence (ClarkeStewart \& Fein, 1983; Scarr, 1985), although other researchers have reported 
that out-of-home care experiences positively influence the degree of involvement with peers (Finkelstein et al., 1978; Harper \& Huie, 1986; Schindler et al., 1987), a finding that we were again unable to replicate in this sample of Swedish preschoolers.

As noted in the introduction, we expected that quality of care would be much more predictively informative than would the type of care. This was indeed the case. In the analyses reported here, as in the analyses earlier reported involving the complete sample of 140 (Lamb et al., 1988), the quality of home care had a significant impact on both social skills and reported personality traits. The most consistently informative variable was the score on Caldwell's HOME inventory. Coefficients for the Belsky and Walker checklist scores tended to be both more modest and inconsistent, whereas the degree of paternal involvement was negatively associated with social skills and positively associated with ratings of greater personality maturity by the mothers. Perhaps in an effort to ameliorate the situation, fathers may become more involved in child care when their children show poor peer skills.

Vandell, Henderson, and Wilson (1987) found that the quality of day care experienced by 204 -year-olds was related to ratings of empathy, social competence, and social acceptance four years later. In a study of 3-, 4-, and 5-year-old American children, Kontos (1987) reported that the quality of alternative care had little impact, whereas family background characteristics had an impact on measures of intellectual and language development. Similarly, in our earlier report involving analyses through the phase II assessments (average age $=\mathbf{2 8}$ months) on data from the complete sample, Lamb et al. (1988) reported that the quality of alternative care had no significant impact on social competence. By contrast, the analyses reported here reveal significant associations between quality of alternative care and both of the outcome latent variables. Perhaps the differences are attributable to the more restrictive sample selection procedures employed here: the earlier analyses, by including children even when their group assignment changed before follow-up, may have been rendered less sensitive as a result.

It should also be noted that the internal coefficients of the alternative care latent variable indicators were inconsistent and somewhat counterintuitive in the analyses reported above. They indicate, for example, that sociable children spent more time in out-of-home care, as would be expected (e.g., Schindler et al., 1987), but had lower scores on the Belsky positive (unexpected) and Belsky negative (expected) checklists. Personality maturity was facilitated by greater number of hours in out-of-home care, by lower scores on the Belsky positive index, and by higher scores on the Belsky negative index. Thus, although the quality of care latent variable had significant coefficients in the predictive models, the results did not support the intuitive prediction that high quality alternative care would have positive effects on social competence, as measured here. 
Instead, our results raise questions about the validity of the Belsky and Walker (1980) checklists as measures of the quality of care. In future analyses, we plan to address this question empirically by examining associations between Belsky scores and various more static measures of quality, including staff turnover rates, staff experience and training, and the like. As emphasized in our earlier report (Lamb et al., 1988), however, Swedish alternative care facilities are all exceptionally good by U.S. standards, and it is thus possible that the limited variability tapped by our measures does not really represent meaningful variations in the quality of care received. Indeed, it has become clear that the homogeneity among the Swedish out-of-home care facilities makes this culture a poor choice for research emphasizing the quality of out-of-home care.

Reported support had a modest association with outcome in our analyses, especially when personality maturity was the outcome measure. Variations in internal coefficients across analyses preclude specifying the type of support that was most influential. The generally positive influence of available social support is consistent with our predictions. Researchers have previously shown that high levels of available support enhance the quality of parental behavior (e.g., Crockenberg, 1981) and our results indicate that this may in turn have a desirable impact on children's personality maturity. In our study, girls were observed to be more sociable and cooperative than boys-a finding that was not specifically predicted when the study was designed. However, others have reported that girls mature psychologically somewhat more rapidly than boys do, so our results are consistent in this regard.

Overall, our results confirm that, in and of itself, knowledge of the type of care received by children from the middle of the second year of their lives is of little value in predicting subsequent social competence. Such outcomes can be better understood when we know something about the quality of care received at home, the child's gender, the supportiveness of the family's social network, and prior measures of the child's social competence. Specific characteristics of the care facilities also aid prediction, although the interpretation of these associations is unclear.

\section{REFERENCES}

Belsky, J. (1986). Infant day care: A cause for concern? Zero to Three, VI(5), 1-9.

Belsky, J. (1987). Risks remain. Zero to Three, VII(3), 22-24.

Belsky, J., Steinberg, L., \& Walker, A. (1982). The ecology of day care. In M.E. Lamb (Ed.), Nontraditional families (pp. 71-116). Hillsdale, NJ: Erlbaum.

Belsky, J., \& Walker, A. (1980). Infant-toddler center spot observation system. Unpublished manuscript, Department of Individual and Family Studies, Pennsylvania State University, University Park, PA 16802.

Block, J., \& Block, J. (1979). Instructions for the California child Q-set. Unpublished manuscript, Institute of Human Development, University of California, Berkeley, CA 94720. 
Block, J.H., \& Block, J. (1980). The role of ego-control and ego-resiliency in the organization of behavior. In W.A. Collins (Ed.), Minnesora symposium on child psychology, Vol. 13 (pp. 39-101). Hillsdale, NJ: Erlbaum.

Bookstein, F.L. (1986). The elements of latent variable models: A cautionary lecture. In M.E. Lamb, A.L. Brown, \& B. Rogoff (Eds.), Advances in developmental psychology, Vol. 4 (pp. 203-230). Hillsdale, NJ: Erlbaum.

Broberg, A., \& Hwang, C-P. (1987). Barnomsorg i Göteborg (Rapport Nr. 5). Psykologiska Institutionem, Göteborgs Universitet, Göteborg, S40020, Sweden.

Caldwell, B.M. (1970). Instruction manual: HOME inventory for infants. Little Rock, AR: College of Education, University of Arkansas.

Caldwell, B.M., \& Bradley, R. (1979). Home observation for measurement of the environment. Little Rock, AR: College of Education, University of Arkansas.

Caldwell, B.M., \& Bradley, R. (1984). Home observation for measurement of the environment (rev, ed.). Little Rock, AR: College of Education, University of Arkansas.

Clarke-Stewart, K.A., \& Fein, G.C. (1983). Early childhood programs. In M. Haith \& J.J. Campos (Eds.), Infancy and developmental psychobiology (pp. 917-999). Vol. II in P.H. Mussen (Gen. Ed.), Handbook of child psychology. New York: Wiley.

Cochran, M.M. (1977). A comparison of group day and family child-rearing patterns in Sweden. Child Development, 48, 702-707.

Colletta, N.D., \& Gregg, C.H. (1981). Adolescent mothers' vulnerability to stress. Journal of Nervous and Mental Discases, 169, 50-54.

Crnic, K.A., Greenberg, M.T., \& Ragozin, A.S. (1981, March). The effects of stress and social support on maternal attitudes and the mother-infant relationship. Paper presented to the Society for Research in Child Development, Boston.

Crockenberg, S.B. (1981). Infant irritability, mother responsiveness, and social support influences on the security of infant-mother attachment. Child Development, 52, 857-865.

Elardo, R., Bradley, R., \& Caldwell, B.M. (1975). The relation of infants' home environments to mental test performance from six- 10 thirty-six months: A longitudinal analysis. Child Development, 46, 71-76.

Elardo, R., Bradley, R., \& Caldwell, B.M. (1977). A longitudinal study of the relation of infants' home environment to language development at age three. Child Development, 48, 595-603.

Finkelstein, N.W., Dent, C., Gallagher, K., \& Ramey, C.T. (1978). Social behavior of infants and toddlers in a day care environment. Developmental Psychology, 14, 257-262.

Frodi, A.M., Lamb, M.E., Hwang, C.-P., Frodi, M., Forsstrom, B., \& Corry, T. (1982). Stability and change in parental attitudes following an infant's birth into traditional and nontraditional Swedish families. Scandinavian Journal of Psychology, 23, 53-62.

Goelman, H. (1988). A study of the relationships between structure and process variables in home and day care settings on children's language development. In A. Pence (Ed.), The practice of ecological research: From concepts to methodology (pp. 16-34). New York: Teachers College Press.

Goelman, H., \& Pence, A.R. (1987). Some aspects of the relationships between family structure and child language development in three types of day care. In D.L. Peters \& S. Kontos (Eds.), Advances in applied developmental psychology: Vol. 2. Continuity and discontinuity of experience in child care. (pp. 129-146) Norwood, NJ: Ablex.

Harper, L.B., \& Huie, K.S. (1985). The effects of prior group experience, age, and familiarity on the quality and organization of preschoolers' social relationships. Child Development, 56, 704-717.

Hollingshead, A.B. (1975). The four factor index of social position. (Manuscript available from the Department of Sociology, Yale University, New Haven, CT 06520.)

Holloway, S.D., \& Reichhart-Erickson, M. (1988). The relationship of day-care quality to children's free play behavior and social problem solving skills. Early Childhood Research Quarterly, 4, 39-54.

Howes, C. (1980). Peer play scale as an index of complexity of peer interaction. Developmental Psychology, 16, 371-372. 
Howes, C., \& Olenick, M. (1986). Family and child care influences on toddlers' compliance. Child Development, 57, 202-216.

Howes, C., \& Stewart, P. (1986). Child's play with adults, toys, and peers: An examination of family and child care influences. Unpublished manuscript, School of Education, University of California at Los Angeles.

Jöreskog, K.G., \& Wold, H. (Eds.). (1982). Systems under indirect observation: Causality, structure, prediction (Vols. 1 and 2). Amsterdam: North Holland.

Kontos, S.J. (1987, April). Day care quality, family background, and children's development. Paper presented to the Society for Research in Child Development, Baltimore, MD.

Kontos, S.J., \& Fiene, R. (1987). Predictors of quality and children's development in day care. In D. Phillips (Ed.), Quality indicators of child care. Washington, DC: National Association for the Education of Young Children.

Lamb, M.E., Frodi, A.M., Hwang, C.-P., \& Frodi, M. (1983). Interobserver and test-retest reliability of Rothbart's infant behavior questionnaire. Scandanavian Journal of Psychology, 24, 153-156.

Lamb, M.E., Hwang, C.-P., Bookstein, F.L., Broberg, A., Hult, G., \& Frodi, M. (1988). Determinants of social competence in Swedish preschoolers. Developmental Psychology, 24, 58-70.

Lamb, M.E., Pleck, J.H., \& Levine, J.A. (1985). The role of the father in child development: The effects of increased paternal involvement. In B.B. Lahey \& A.E. Kazdin (Eds.), Advances in clinical child psychology, Vol. 8 (pp. 229-266). New York: Plenum.

Lamb, M.E., Sternberg, K.J., \& Knuth, N. (1988). Toddler social behavior and the quality of family day care. Unpublished manuscript, National Institute of Child Health and Human Development, Bethesda, MD.

Lamb, M.E., Thompson, R.A., Gardner, W., \& Charnov, E.L. (1985). Infant-mother attachment. Hillsdale, NJ: Erlbaum.

MacDonald, K,, \& Parke, R.D. (1984). Bridging the gap: Parent-child play interaction and peer interactive competence. Child Development, 55, 1265-1277.

McCartney, K. (1984). Effect of quality day care environment on children's language development. Developmental Psychology, 20, 244-260.

McCartney, K., Scarr, S., Phillips, D., Grajek, S., \& Schwarz, J.C. (1982). Environmental differences among day care centers and their effects on children's development. In E.F. Zigler \& E.W. Gordon (Eds.), Day care: Scientific and social policy issues (pp. 126-151). Boston: Auburn House.

Parke, R.D., MacDonald, K.B., Beitel, A., \& Bhavnagri, N. (in press). The role of the family in the development of peer relationships. In R. DeV. Peters \& R.J. McMahon (Eds.), Marriages and families: Behavioral treatments and processes. New York: Brunner/ Mazel.

Phillips, D. (1987). Quality in child care: What does research tell us? In D. Phillips (Ed.), Quality indicators of child care. Washington, DC: National Association for the Education of Young Children.

Phillips, D., McCartney, K., Scarr, S., \& Howes, C. (1987). Selective review of infant day care research: A cause for concern. Zero to Three, VII(3), 18-21.

Radin, N. (1982). Primary caregiving and role-sharing fathers. In M.E. Lamb (Ed.), Nontraditional fomilies: Parenting and child developmem (pp. 173-204). Hillsdale. NJ: Erlbaum.

Robinson, J.P. (1977). How Americans use time: A socio-psychological analysis. New York: Praeger.

Rothbart, M.K. (1981). Measurement of temperament in infancy. Child Development, 52, 569-578.

Rothbart, M.K. (1986). Longitudinal observation of infant temperament. Developinental Psychology, 22, 356-365.

Scarr, S. (1985). Mother care/other care. New York: Basic Books.

Schindler, P.J., Moely, B.E., \& Frank, A.L. (1987). Time in day care and social participation of young children. Developmental Psychology, 23, 255-261. 
Stevenson, M.B., \& Lamb, M.E. (1979). Effects of infant sociability and the caretaking environment on infant cognitive performance. Child Development, 50, 340-349.

Thomas, A., Chess, S., Birch, H., Hertzig, M.E., \& Korn, S. (1963). Behavioral individuality in early childhood. New York: New York University Press.

Thompson, R.A., \& Lamb, M.E. (1983). Security of attachment and stranger sociability in infancy. Developmental Psychology, 19, 184-191.

Thompson, R.A., \& Lamb, M.E. (1984). Continuity and change in socioemotional development during the second year. In R.N. Ende \& R.J. Harmon (Eds.), Continuities and discontinuities in development (pp. 315-338). New York: Plenum.

Tinsley, R.B., \& Parke, R.D. (1984). Grandparents as support and socialization agents. In M. Lewis (Ed.), Beyond the dyad (pp. 161-194). New York: Plenum.

Tinsley, R.B., \& Parke, R.D. (in press). Grandparents as interactive and social support agents for families with young infants. International Journal of Aging and Human Development.

Vandell, D.L., Henderson, U.K., \& Wilson, K.S. (1987, April). A follow-up study of children in excellent, moderate and poor quality day care. Paper presented to the Society for Research in Child Development, Baltimore, MD.

Wold, H. (1975). Path models with latent variables: The NIPALS approach. In H.M. Blalock (Ed.), Quantitative sociology: International perspectives on mathematical and statistical modeling (pp. 307-357). New York: Academic.

Zigler, E.F., \& Child, I.L. (1973). Socialization and personality development. Reading, MA: Addison-Wesley. 